\title{
IMPLEMENTING CLEANER PRODUCTION AS AN ENVIRONMENTAL MANAGEMENT EFFORTS IN SMALL INDUSTRIES OF CASSAVA CHIPS
}

\author{
Erina Rahmadyanti ${ }^{1}$ and Andre Dwijanto W. ${ }^{2}$ \\ ${ }^{1}$ Department of Civil Engineering, Faculty of Engineering, State University of Surabaya, Indonesia \\ ${ }^{2}$ Departement of Management, Faculty of Economic, State University of Surabaya, Indonesia \\ E-mail: erinarahmadyanti@unesa.ac.id
}

\begin{abstract}
Small and Medium Enterprises (SMEs) is one of the major driving factors for Indonesian economy, especially in food processing industries. The cassava-based industry is one type of food and beverage industry with chips as its major product. The limitations of knowledge caused their activities to only aim at pursuing economic benefits and ignoring the environmental balance. The most appropriate preventive method used, according to the characteristics of SMEs in Indonesia, is Cleaner Production. This study aims to reduce the risk of environmental pollution caused by the waste production of small chips industries by implementing cleaner production. The method used in this study is quick scanning by analyzing mass balance, energy, and utilities that aim to find an inefficient process to minimize losses. Implementation of cleaner production may include good housekeeping, reducing, and reusing. Based on the assessment of alternative eligibility criteria, the equipment modifications are the main factor in implementing cleaner production that drives the profits by providing efficiency of cutting as much as 80 percent and optimizes the profits into $57.62 \mathrm{~kg}$ in a month or $691.44 \mathrm{~kg}$ in a year. If the price of cassava chips is IDR 40,000 in a $\mathrm{kg}$, then it would save IDR 27,657,600 in a year.
\end{abstract}

Keywords: small industries, cassava chips, cleaner production.

\section{INTRODUCTION}

Indonesia's current economic structure is primarily focused on agriculture and industries which extract and harvest natural resources. There are only limited industries which focused on products with added value. In addition to this, there is a development gap between western and eastern parts of Indonesia. Masterplan for Acceleration and Expansion of Indonesia Economic Development 2011-2025 (MP3EI) is aimed at accelerating and expanding the economic development in Indonesia as a starting point towards making the nation more equitable. As a country consisting of thousands of islands, the Indonesian archipelago has a unique combination of economic with specific major islands or regions having its own strategic future role in achieving Indonesia vision. By taking into consideration these potentials and strategic roles of each major island, there are six corridors that have been identified as follows: Sumatra economic corridors, Java economic corridors, Kalimantan economic corridors, Sulawesi economic corridors, Bali-Nusa Tenggara economic corridors, and Papua-Kepulauan Maluku economic corridors (Coordinating Ministry For Economic Affairs, 2011).

The prime purpose of MP3EI is to enable Indonesia to become a developed and prosperous country with a national GDP of around USD 4-4.5 Trillion in 2025 and becoming the 9th largest economies in the world. To achieve this goal, approximately 82 percent or equivalent to USD 3.5 Trillion will be targeted as a contribution to GDP from economic corridors. By implementing MP3EI, Indonesia's overall GDP is expected to grow more rapidly and broader, both for areas within the six corridors and for areas outside the corridors. By applying MP3EI, the annual national GDP growth will be approximately 12.7 percent nationally with regional growth within the corridor at 12.9 percent. Growth in the areas outside of the corridors would also increase by 12.1 percent as a result of the spillover effects of economic development within the corridors areas (Coordinating Ministry For Economic Affairs, 2011).

Driver for national industry and services provision are main themes of the Java economic development corridor. East Java province as part of the Java corridor should contribute the success of the economic development. Although Indonesia's fundamentals are strong, achieving a high level of growth will not happen automatically. A number of challenges must be overcome in order to realize the sustainable development for a successful Indonesia. To support this, a special strategy will be implemented to further develop Java corridor industries that support the conservation of water and the environment.

One of the main focus of Java corridor development will be on food and beverage industry. Food and beverage industry in Indonesia, including in East Java province is dominated by thousands of small and medium enterprises (SMEs). SMEs play an important role in the production, innovation, and employment creation. SMEs are enterprises classified as having fewer than 50 employees; make up 80-90 percent of all industrial establishments in most countries (Behnsen et al. 2002).

The role of SMEs has also been actualized in the past to the present crisis. During times of economic crisis up to now, SMEs are able to stand as a major driving factor for the Indonesian economy. Especially when the crisis investment and government spending is very limited, then the role of SMEs as a form of the people's economy is very large. Furthermore, SMEs contributes for about $56.7 \%$ and non-oil exports contribute more about $15 \%$. However, in the range of entrepreneurship, SMEs still donate $99 \%$ and has a $99.6 \%$ share in employment (Indonesians statistic, 2011). Although SMEs constitute the backbone of an economy, they also account for the bulk of human resources and 
polluting activities of the environment (Sohair et al, 2007). In the other hands, The Asian Development Bank (ADB) notes that most of the pollution in the Asian countries comes from SMEs, and is especially concentrated in its megacities (ADB, 2000). Environmental problems that generally occur in the food and beverage industries are (Ramjeawon, 2000): 1.) high water consumption, especially problematic in water-poor or water-stressed countries; 2.) the generation of liquid effluent with high organic content; and 3.) the generation of large quantities of sludge and solid wastes.

Their environmental impact may not be great, but their cumulative impact is substantial. It is caused by several factors including lack of access to resources allowing for investments in pollution control, low level of technology, lack of space, unavailability of trained personnel, and the unwillingness of management to invest in environmental protection (Ramjeawon, 2004). In 1987, the United Nations published a document that challenged the economy orthodoxy of the relationship between development and environmental degradation. Called Our Common Future, it emphasized the concept of 'sustainable development'. In theory, sustainable development simply means meeting the needs of the present generation, without compromising the needs of future generations. The true challenge of sustainable development lies in putting the theory into practice.

In order to compete with larger enterprises in the market, SMEs should perceive environment-oriented management, regard as cost intensive that hampers innovation and development. Competition for capital and new investment opportunities is driving the environmental performance of SMEs in the 21 st century. Achieving this objective requires financial performance and a commitment to innovation and best practice. Also, sustainability-driven companies achieve their business goals by integrating economic, environmental and social growth opportunities in a pro-active, cost-effective and responsible manner today, so they will outpace their competitors and be tomorrow's winners (Abou-Elela, 2002 and Sohair et al, 2007). To achieve such goals, the implementation of pollution prevention measures, cleaner production, and low-cost treatment technologies are required (Abou-Elela, 2002).

SMEs limitations require an easy method as a preventive action to protect the environment. Several advantages obtained when implementing various preventive action are (Fresner et al, 2010): 1) reducing waste and emission generally means using smaller quantities of materials and energy, which has the potential for economic savings; 2.) reduction of waste and emissions usually triggers an innovative process in the company because of the intensive focus on the analysis production processes; 3) risks regarding environmental liability and disposal are reduced to a minimum; 4.) reduction of waste and emissions means moving towards sustainable economic development.

The most appropriate preventive method is used to the characteristics of SMEs in Indonesia is Cleaner Production. The SMEs should adopt cleaner production methods compared to the traditional end of pipe approaches to pollution control. Cleaner production offers an opportunity for win-win solutions as SMEs reduce their operational costs and environmental and other liabilities by using less energy, water and materials, handling chemicals and their waste safely and generating less waste and pollutants (Van Berkel, 2011). Cleaner production is commonly achieved through a diversity of practice, including good housekeeping, process and/or equipment modification, input material substitution, on-site reuse and recycling and change in product and/or technologies (Van Berkel, 2007a,b). Cleaner Production techniques are dynamic, and although industries have improved their environmental performance over the last two decades, there is continuing room for improvement.

Cleaner Production has been widely applied in various industries of cassava, but the majority in cassava starch. On the other hand, there are some industries that also produce derivative products of cassava besides flour including cassava chips. Previous studies related to the implementation of cleaner production in cassava chips industry is still limited, especially in small industries. Therefore, the cleaner production method may still be developed in this industry, especially in small industries of cassava chips which vary process depending on the origin of the production areas.

Cassava is the fourth most important source of calories in the tropics after rice, wheat, and maize (Okunade dan Adekalu, 2013). Cassava production in Indonesia makes up about 30 percent of the production of Asia and the Pacific, and Indonesia is the fourth largest cassava exporter in the world. The total amount of production is almost the same as Thailand's, the world largest cassava exporter, however, Indonesia's cassava export is less than 10 percent of Thailand's (based on FAOSTAT, http://faostat.fao.org in Sugino and Maerowani, 2009). Production can be observed in all over the country, but the major production area is located in the islands of Sumatra and Java). East Java is one of the provinces with the largest area of cassava production in Indonesia which produced 20 percent of the national output (Indonesia statistics, 2006). Implementation of cleaner production in cassava-based small medium industries in East Java province will increase the competitiveness of the products. This will have an impact on increasing the contribution of the province of East Java in strengthening the national economy.

Cassava contains cyanide which limits utilization in the fresh unprocessed form. The roots need to be processed to reduce the cyanide content to safe levels before consumption. Once harvested, cassava tubers begin to deteriorate and can not be stored for more than a few days. They are bulky with about 70 percent moisture content which makes transportation of the tubers to urban markets difficult and expensive. Thus, there is a need for rapid processing of the tubers (before spoilage sets in) into various products with increased shelf life. These shelfstable products are easier to transport and market and cost less to transport and contain less cyanide (Udoro, Gbadamosi, and Taiwo, 2008). Cassava-based small and medium industries in East Java produces three major products namely chips, crackers, and flour.

Cassava chips are unfermented, dry products of cassava. Roots are chipped into smaller sizes for fast drying that also help the process of detoxification. Cassava can be dried naturally by the sun or artificially in an oven (FIIRO, 2005; Irinkoyen et al, 2008). In some countries, chips are utilized in the production of flour and starch. 
Traditionally, cassava is processed into dry whole roots that have undesirable color, irregular shapes and are often contaminated with dust. Production of chips by SMEs traditionally includes the steps of peeling, washing, slicing, seasoning, frying, oil draining, and sorting. The process of washing and seasoning results in the production of wastewater. Most cassava processing industry discharges significant quantities of wastewater whose major component is cyanide to rivers, lakes, sewage canals, agricultural fields and the environments which eventually flows back to streams or downstream surface water locations (Oliviera et al., 2001 in Okunade and Adekalu, 2013). This will lead to contributing significantly to environmental pollution and depletion of water resources as they contaminate surface water, particularly during dry seasons. Currently, there is no specific method of disposal or treating the cyanide-laden wastewater resulting from cassava. In addition to waste water, production processes produce waste in the form of chips cassava outer shell and the remaining pieces of the slicing process. The resulting wastes are often left in mounds which generate a highly offensive odor and are rather unsightly.

One of the strategic measures to reduce cyanide content of processed cassava is to improve processing methods used for conversion of roots storable cassava product such as chips and flour. A number of processing methods or a combination of them (peeling, slicing, retting, fermentation, boiling, drying, roasting, pounding, milling etc) are available that attempt to remove poisonous principle as much as possible (Amsalu and Esubalew, 2011). Cassava contains the potentially toxic compound like cyanogenic glycosides. These compounds can cause acute cyanide poisoning and death in humans and animals when consumed in sufficient quantities (White et al, 1998 in Amsalu and Esubalew, 2011). This study aims to reduce the risk of environmental pollution caused by the waste production of small chips industries by implementing cleaner production.

\section{METHODOLOGY}

A waste audit procedure is a systematic tool used to identify the opportunities of cleaner production. The information from a waste audit can be starting point for investigating pollution issues at any facility. Such an assessment of waste generation as well as raw material and energy consumption can highlight areas for potential intervention and provide a baseline for comparing subsequent increases or decreases in specific waste stream Based on the UNEP's Audit and Reduction Manual for Industrial Emissions and Waste (1991) and other relevant literature (UNEP, 1991), the methodology to be used in this study to identify waste streams and energy usage were developed and implemented. The method used in this study is quick scanning by analyzing mass balance, energy, and utilities that aim to find an inefficient process to minimize losses.

Data for material and energy balances often can be taken from accounts (for a year), but have to be weighed and measured for more detailed balances. This makes this step time consuming and sometimes difficult in practice if process documentation is not in place and has to be developed for the cleaner production project (Fresner, 2010).
All the record of production for a 12-month period were used for the audit. All the available information resources (raw material purchase records, product quantities, water usage and wastewater discharge data, etc), as well as the checklist and personal interviews, were used to gather all the available data for the mass balances. A data collection from the mass balance are translated into a waste reduction plan.

\section{RESULTS}

The process outputs from each of cassava chips unit operation were quantified in the following figure:

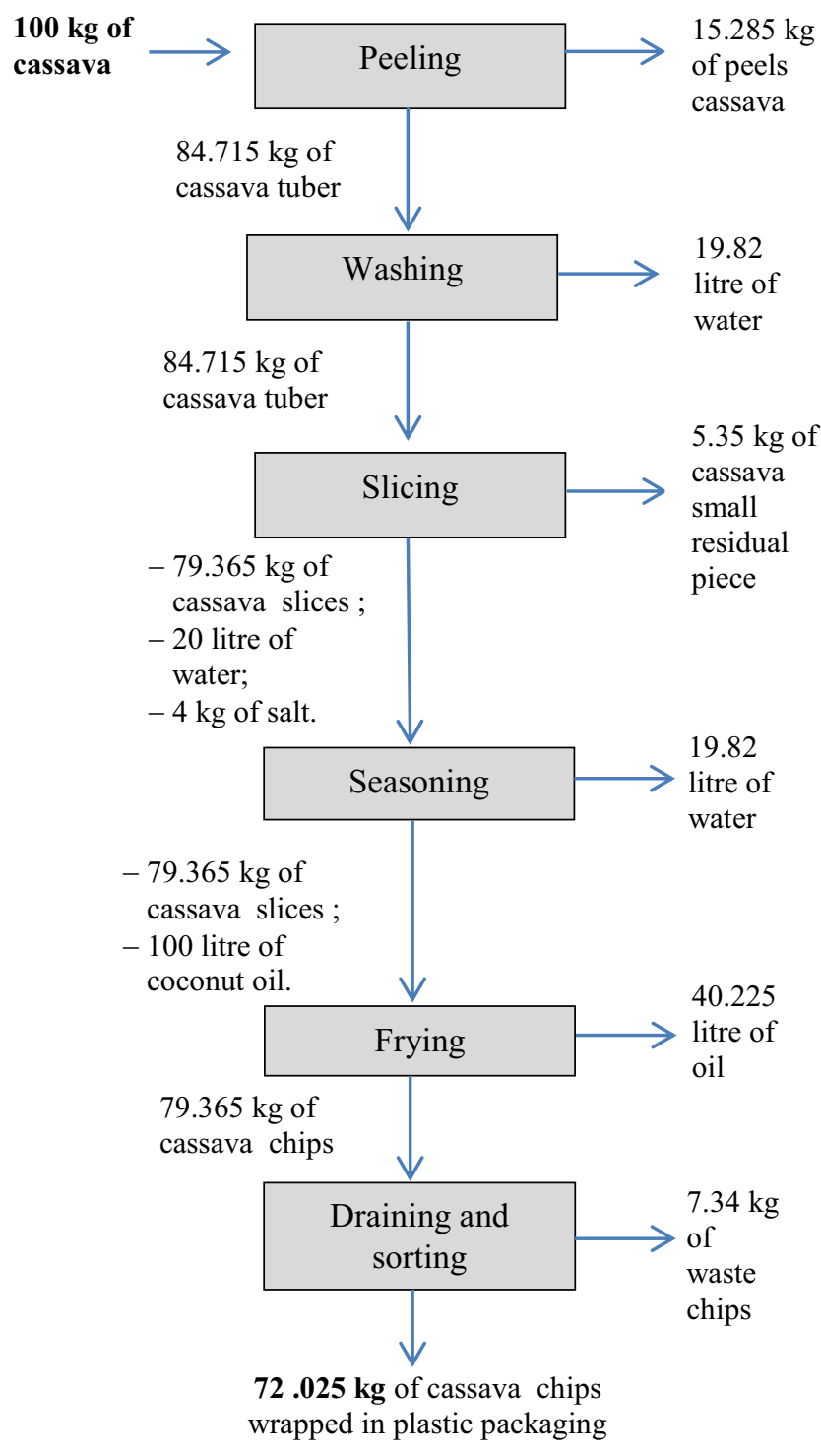

Figure-1. Mass balance at every stage of the production of cassava chips.

\section{Peeling}

This peeling process is manually done using the knife. For every $100 \mathrm{~kg}$ of cassava, production process generates waste as much as $15.285 \mathrm{~kg}$ of cassava peel. Peeled cassava is then soaked in a tub of water for washing. 


\section{Washing}

The washing process is gradually done until the whole amount of $84.715 \mathrm{~kg}$ of cassavas is completely cleaned. Gradual immersion process requires 10 pieces sized 25-litre bucket filled water. During this process, it wastes 19.82 liters of water.

\section{Slicing}

The whole cassava which amount $84.715 \mathrm{~kg}$ cut using the manual cutter designed in circular thin. The slicing process produces small residual pieces as much as $5.35 \mathrm{~kg}$.

\section{Seasoning}

The soaking process of $79.365 \mathrm{~kg}$ cassava slices in shaped thin circle into 20 liters water which has been given saline $4 \mathrm{~kg}$ and whiting $2 \mathrm{~kg}$ takes 1 hour to make the salt seep into slices and whiting is able to reduce the water content in cassava. After 1 hour, it is drained and sliced using an ordinary filter before fried. In this process, the waste water soaking is 18.326 liters.

\section{Frying}

Frying is done twice by using $50 \mathrm{~kg}$ of cooking oil. $79.365 \mathrm{~kg}$ cassavas are gradually fried until cooked. The frying process is done in two stages. The first stage uses $25 \mathrm{~kg}$ cooking oil and takes 15 minutes before subsequently drained by the filter. The second stage uses $50 \mathrm{~kg}$ cooking oil which has been heated for 10 minutes before used to fry the chips. The remaining oil from the frying process is $40.225 \mathrm{~kg}$ and would be a waste the third use. These processes use a frying pan with the diameter of $50 \mathrm{~cm}$ heating energy source of Liquid Petroleum Gas (LPG) are placed side by side.

\section{Draining and sorting}

$79.365 \mathrm{~kg}$ of cassava that has been fried subsequently drained of its oil use newspaper until losing the heat then sorting the chips and packing it using $1 \mathrm{~mm}$ polypropylene plastic. The sorting process aims to select chips that may be damaged by frying. This last process produces $72.025 \mathrm{~kg}$ cassava chips.

\section{DISCUSSIONS}

\section{Waste Identification}

Wastes produced by this cassava chips industry are cassava peel, residual water from washing and soaking, pieces of cassava from the slicing process, remaining cooking oil, and pieces of cassava chips from frying.

Cassava peel waste produced is $15.285 \mathrm{~kg}$ per day, but this waste is not discharged into the environment because it is taken by local farmers using as cattle feed. The wastewater from washing or soaking along with the remaining of seasoning are directly discharged into a small drainage channel away without any processing. This liquid waste is composed of 19.82 liters of water containing dissolved cassava starch and 18.326 liters of water marinade which contains salts and whiting. Cassava pieces that can not be sliced into chips are dried using the sun for 7 days to be stored in sacks and powdered. The flour is used to make cakes for own consumption.
Cooking oils used in the frying process will be the waste after 3 times used, because, after the third use, the cooking oil will change the color of cassava chips, decrease the quality of taste, and make the products become not good for consumption. The waste of cooking oil is collected around $80.45 \mathrm{~kg}$ per week into four plastic containers of 25 liters.

In the final production process, the pieces of damaged or burnt chips because of the frying process showed the efficiency of the production process. This can be minimized by using good equipment that has the ability to cut into same thickness, yet it results in the same size and same cooking time.

\section{Opportunities in implementing cleaner production}

Implementing cleaner production in cassava chips industry prevents or minimizes environmental impacts through the product life cycles from raw material to be a product until final disposal. The strategy applied in cassava chips industry are strategies to look at the process and the final product.

The strategy carried out by observing the damage prevention process in the form of raw materials, minimizing energy use, eliminating the use of raw materials that are poisonous and dangerous as well as reducing levels of toxins contained within the emissions and waste before leaving the process. Strategy on the final product includes reducing environmental impact throughout the product cycle from the manufacture of the product until final disposal.

\section{Feasibility assessment}

\section{Technical feasibility}

Technical feasibility assessment is done by weighting towards the implementation of cleaner production. Some cleaner production alternatives offered by the condition of technical support. Technical analysis of these alternatives are:

\section{Good-housekeeping}

Good-housekeeping implemented aims to keep the environment from potentially contaminated in the various stages of the production process. Water spills on residual leaching or soaking cassava seasoning is one of the stages that could potentially contaminate the environment. At the production area, the majority of SMEs typically have clay floor which used in displacement washing and soaking location adjacent seasoning with a floor made of cement layer so it is easy to clean. Washing and soaking in the production process are done at the same hygiene which does not meet any safety standards because the clay floor spilled water may become slippery. The technical aspect for maintaining cleanliness is important to note as well as owners and workers require awareness.

\section{Improving operation procedures}

This effort is minimizing the impact on the effectiveness of production time. Production can be done every day with each operation process timing appropriately. This improvement can also be done by creating a Standard Operation Procedure (SOP) in 
implementing production process. Standard is the basis for labor in doing his job.

\section{Equipment modifications}

Modification of the equipment is required to minimize the residual pieces of cassava slicing process. In the process of production, every $100 \mathrm{~kg}$ of cassava produced $5.35 \mathrm{~kg}$ of small pieces per day. If production is done every day, in a month it will produce $160.5 \mathrm{~kg}$ of waste. It means the waste produced during the one-month production process is about $150 \%$ of the raw materials a day.

At this present, the waste is dried using sunlight just above the bamboo to be made into flour and use to make various cake for own consumption. The waste is quite a lot because of the unstandardized equipment for cutting process. In this process, the cutting blades are assembled or can be said to be conventional. By using the conventional tools, the waste produced also affect the next process of soaking and frying. Only because of the cutting tool used cannot produce pieces with the same thickness, this condition will get worse if the process is done by five different workers.

The different thickness of Cassava slice will affect the absorption of seasoning and the cooking time. Therefore, as expected that after the frying process, the chips will be found into a different level of cooked, such as sufficiently cook, evenly cooked, and charred. Overall, cutlery affects the quality of cassava chip products. Failure to redesign the equipment will potentially reduce the profits earned by the owner of SMEs.

\section{Reuse leftover cooking oil}

In the production of cassava chips, the owners do not reuse cooking oil for frying. It because after being used for three times the cooking oil will affect the color of cassava chips though the color of the remaining cooking oil is still clear. The owner of SMEs agreed to maintain the quality of the products to give satisfaction to the consumers. The waste of cooking oil is $80.45 \mathrm{~kg}$ per week and in a month it becomes $321.8 \mathrm{~kg}$. This leftover cooking oil is purchased by others for the production of liquid soap. Waste cooking oil is purchased at a price of IDR $50,000.00 /$ plastic containers.

\section{Economic feasibility}

Assessment is based on the economic feasibility of the profits and payback periods. Earnings calculation is done by comparing the earning before and after implementing cleaner production. The SMEs incomes through cassava chips production prior to implementing cleaner production is about IDR $150,000,000.00$ in a year. Production cost in a year is IDR $68,800,000.00$ so the profits is IDR $81,200,000$ in a year.

\section{Good-housekeeping}

Good housekeeping is applied to the spill or spills of water in the washing process and soaking seasoning, divert the process that is originally located above the clay floor into place with cement floor which is only 2 meters away from the pan. Although the spilled water does not affect the profits but it causes unhygienic environment.

\section{Improving operation procedures}

Improving operation procedures for the production process has no effect on the economic or financial savings but on the contribution of efficiency which gains by the workers in the production process of cassava chips.

\section{Equipment modification}

Equipment modifications done is by introducing a slicer machine to replace conventional mower. It aims to minimize the wasted pieces on every production process. Slicer machine has a capacity of $50 \mathrm{~kg}$ per hour by using an electrical operating power of 250 watts. This means that the process of slicing the raw material for a total of $100 \mathrm{~kg}$ per day only takes 2 hours.

The production process for one month would require as much as $15 \mathrm{kWh}$ of electricity supply. If electricity tariff (TDL) for households in 2015 amounted to IDR 1321.00, within one month (30 days of production) the costs required for the machine slicer is IDR 1.9815. A very low cost compared to the loss resulted by conventional cutting knives. Slicer machine is assumed to be able to minimize the waste disposed of by 80 percent as part of a cutter that uses stainless steel materials are designed to be able to set its thickness so it cuts the same thickness optimally. This slicer machine has a payback period 0.083 years or about 1 month then the cost by using this technology can be returned. The use of this equipment for the SMEs also does not require power adjustment because power is managed by $1.300 \mathrm{kWh}$.

\section{Reuse leftover cooking oil}

Purchasing leftover cooking oil by the liquid soap manufacturer gives its own profits for the owner of SMEs because the leftover cooking oil from the production process of cassava chips is purchased for about IDR 200,000 or about IDR 800,000 in a month.

\section{Environmental feasibility}

Selection of cleaner production alternatives based on the environment consideration namely through the introduction of machine slicer, good housekeeping, and reuse of leftover cooking oil. There are alternatives related to the environmental advantages of cleaner production: 1) the efficiency of water; 2) the efficiency of electricity use; 3) sanitation and hygiene company and workers; and 4) capacity of the environment use.

\section{Implementing cleaner production}

Some cleaner production alternatives offered can be implemented in accordance with the results of the feasibility assessment. Alternative production that showed the highest score is the modification of equipment. This alternative is easily implemented by SMEs.

\section{CONCLUSIONS}

Based on the previous discussions, it can be concluded that the SMEs of cassava chips are not familiar with cleaner productions. Implementation of cleaner production may include good housekeeping, reducing, and reusing. From the assessment of alternative eligibility criteria, the equipment modifications are the main factor in implementing cleaner production that drives the profits by providing efficiency of cutting as much as 80 percent and 
optimizes the profits into $57.62 \mathrm{~kg}$ in a month or $691.44 \mathrm{~kg}$ in a year. If the price of cassava chips is IDR 40,000 in each $\mathrm{kg}$, then it would save IDR 27,657,600 in a year.

\section{REFERENCES}

Amsalu N and Esubalew G. 2011. Soaking and drying cassava roots reduced cyanogenic potential of three cassava varieties at Jimma, Southwest Ethiopia. World Journal of Agricultural Sciences 7(4):439-443.

Asian Development Bank. 2000. Industry and the Environment. Chapter 6 in Asian Environmental Outlook 2001. ADB Report.

Behnsen, A., Hilebrecht, K., Kurzingar E., and Kranert, M. 2002. Waste minimization in small and medium enterprises. International conference of appropriate environmental and solid waste management and technologies for developing countries. Turkey, Istanbul: ISWA.

Coordinating Ministry For Economic Affairs. 2011. Masterplan for Acceleration and Expansion of Indonesia Economic Development.

FAO. 2000. The world cassava economy: facts, trends, and outlook. Food and Agriculture Organizations of the United Nations. FAO report, pp 7-15.

Fresner J. 2010. The theory of inventive problem solving (TRIZ) as option generation tool within cleaner production projects. Journal of cleaner production 18 (2010) 128-136.

Okunade D.A., and Adekalu K.O. 2013. Physico-chemical analysis of contaminated water resources due to cassava wastewater effluent disposal. European international journal of science and technology 2(6), pp.75-84.

Ramjeawon T. 2004. A case study of cleaner production opprtunities in small and medium enterprises on the island of Maritius. Electronic Green Journal 1(20):1-14.

Sohair I, Abou -Elela, Fayza A.Nasr, Saber A. El-Shafai. 2008. Wastewater management in small-and medium-size enterprises: case studies. Environmentalist 28: 289-296.

Sugino T and Mayrowani H. 2009. The determinants of cassava productivity and price under the farmer's collaboration with the emerging cassava processor: A case study in East Lampung, Indonesia. Journal of Development and Agricultural Economics Vol 1(5), pp.114-120.

Van Berkel R. 2007a. Cleaner Production and EcoEfficiency. In Marinova D, Annandale D, and Phillimore J (eds). The international handbook of environmental technology management. Edward Elgar Publications, Cheltenham, UK, pp 67-93.

Van Berkel R. 2007b. Cleaner Production and EcoEfficiency in Australia small firms. International Journal Environmental Tehnology Manage 7(5-6):672-693.
Van Berkel R. 2011. Evaluation of the global implementatio of the UNIDO-UNEP National Cleaner Production Centres (NCPC) Programme. Clean Technology Environmental Policy 13:161-175.

Udoro E.O., Gbadamosi O.A., and Taiwo A.K. 2008. Studies on the production and utilization of dried cassava chips as human food. International Union of Food Science and Technology.

UNEP, 1991. United Nations Industrial Development Organization's Audit and Reduction Manual for Industrial Emissions and Wastes.

White, W.L.B., D.I.Arias-Garson, J.M. McMahon and R.T. Sayre. 1998. Cyanogenesis in cassava: the role of hydroxy nitrile lyase in root cyanide production. Plant Physiology 116:1219-1225. 